\title{
Health Workers' Perceptions on Where and How to Integrate Tobacco use Cessation Services into Tuberculosis Treatment; A Qualitative Exploratory Study in Uganda
}

Elizeus Rutebemberwa ( $\nabla$ ellie@musph.ac.ug )

Makerere University https://orcid.org/0000-0001-8363-7928

Kellen Nyamurungi

Makerere University School of Law

Surabhi Joshi

Department of Non-Communicable Diseases Division, World Health Organization, Geneva

Yvonne Olando

University of Nairobi

Hadii M. Mamudu

College of Public Health, East Tennesse State University, Johnson City

Robert P. Pack

College of Public Health, East Tennesse State University, Johnson City

Research article

Keywords: Tuberculosis (TB) treatment, tobacco use cessation, integration, health workers

Posted Date: September 30th, 2020

DOI: https://doi.org/10.21203/rs.3.rs-71580/v1

License: (c) (1) This work is licensed under a Creative Commons Attribution 4.0 International License.

Read Full License

Version of Record: A version of this preprint was published at BMC Public Health on July 28th, 2021. See the published version at https://doi.org/10.1186/s12889-021-11502-4. 


\section{Abstract}

Background: Tobacco use is associated with exacerbation of tuberculosis (TB) and poor TB treatment outcomes. Integrating tobacco use cessation within TB treatment could improve healing among TB patients. The aim was to explore perceptions of health workers on where and how to integrate tobacco use cessation services into TB treatment programs in Uganda.

Methods: Between March and April 2019, nine focus group discussions (FGDs) and eight key informant interviews were conducted among health workers attending to patients with tuberculosis on a routine basis in nine facilities from the central, eastern, northern and western parts of Uganda. These facilities were high volume health centres, general hospitals and referral hospitals. The FGD sessions and interviews were tape recorded, transcribed verbatim and analysed using content analysis to identify themes.

Results: Participants indicated that tobacco use cessation activities should be integrated in TB treatment starting from communities when people are still healthy. Cessation should also be implemented in health facilities including referral facilities, and be extended to those who have been healed as they go back to communities. This calls for collaborations beyond health workers to TB treatment supporters, peers and the media.

Conclusions: Tobacco use cessation should take place in communities as well as health facilities. Partnerships with media and families are needed. Health system challenges need to be addressed to support effective implementation.

\section{Background}

Tuberculosis (TB) prevalence has been increasing in Uganda since the 1980s [1], accounting for $4 \%$ of total deaths in health facilities in 2018/2019 [2]. By 2018, TB prevalence nationwide was 200 (118-304) / 100,000 population [3], an increase from 58 (32-91) / 100,000 in 2013 [4]. Smoking has been cited as one of the risk factors contributing to this increase. The prevalence of smoking among patients with TB in Kampala was about $26 \%$ in 2015 [5].

In Uganda, TB treatment is under the TB and Leprosy Control Programme which is in the communicable disease control department while tobacco use cessation is under the docket of the Mental Health and Substance abuse programme in the non-communicable disease department. Tobacco use cessation and TB control programs are not linked [6]. At implementation level, whereas TB treatment is done in health facilities of all levels, tobacco use cessation is expected to be enforced by public health officers, environmental health officers, customs officers and local government officers who operate outside hospitals [7].

The relationship between TB and tobacco use is well-established. A meta-analysis done in 2015 concluded that smoking was a risk factor for TB [8]. There is improved adherence to TB treatment with 
tobacco use cessation $[9,10]$. Smoking has been associated with extensive lung disease [11], less treatment completion [12] and lower TB cure rates [13, 14]. Among patients with multi-drug resistant TB, smoking was associated with increased mortality [15]. In 2009, a study in China indicated an association between TB and tobacco smoking [16] which requires integration of interventions against TB with those against tobacco smoking.

Unfortunately, screening for smoking is not universal in all health facilities [17]. A study from South Africa in 2010 showed that many people seeking treatment in health facilities missed being screened for tobacco use [18]. A review of hospital records in Nigeria indicated poor documentation about tobacco use [19]. A literature review from low and middle-income countries (LMICs) indicated that physicians' advice on quitting smoking was less among those who smoked than those who did not smoke [20].

Advice on tobacco use cessation has been shown to be effective. In a study involving 12 LMICs, physician's advice increased the likelihood for increased utilization of smoking quit-lines, WHOrecommended tobacco use cessation medication, and cessation clinics [17]. Studies in India indicated that patients reduced tobacco use when cessation activities were integrated into TB treatment [21, 22].

Lack of integration is a missed opportunity to support tobacco use cessation among patients with TB. Health workers who work with patients with TB are key stakeholders if tobacco use cessation activities. Physicians' involvement in cessation services increases their uptake [17]. The objective of this study was to explore the perceptions of health workers on where and how tobacco use cessation services can be integrated into TB treatment in Uganda.

\section{Methods}

\section{Study area}

The study was conducted in nine health facilities: two from Kampala, which is the capital city; two from the eastern, three from the northern, and two from the western parts of the country. Three of the facilities were high volume health centres, two were general hospitals and four were regional referral hospitals. One general hospital was owned by a non-governmental organization (NGO) and the rest by the government. All these hospitals were offering primary and secondary level treatment. This is shown in Table 1. 
Table 1

Characteristics of hospitals

\begin{tabular}{|lllll|}
\hline Region & Regional Referral Hospitals & General Hospitals & Health Centre & Total \\
\hline North & 2 & 1 & 0 & 3 \\
\hline Kampala & 0 & 0 & 2 & 2 \\
\hline Eastern & 1 & 0 & 1 & 2 \\
\hline Western & 1 & 1 & 0 & 2 \\
\hline Total & $\mathbf{4}$ & $\mathbf{2}$ & $\mathbf{3}$ & $\mathbf{9}$ \\
\hline
\end{tabular}

\section{Study Design}

This was a qualitative exploratory study conducted using focus group discussions (FGDs) and key informant interviews (KIIs). FGDs are useful in getting perceptions of certain groups over a particular issue [23]. During the FGD, interaction between participants is used to explore their views and whether they coalesce on expressed opinions [24]. When respondents in Klls are well informed, they provide an overall view of the community [25] and are less influenced by the presence of their peers [26].

\section{Study Population}

FGD participants comprised of health workers working in TB clinics or in departments involved in the management of TB patients, such as out-patient departments, admission wards, laboratory, or dispensing section. They were purposively selected. They were mobilized by the head of department of the TB clinic through face-to-face discussions with heads of their respective departments. Department heads forwarded persons with experience in working with TB patients. Heads of departments for TB clinics were the key informant interviewees. This is summarized in Table 2 on participants' sex distribution.

Table 2

Sex of focus group discussions and key informant interview participants

\begin{tabular}{|lll|}
\hline Sex & Frequency (\%) \\
\cline { 2 - 3 } & FGDs (N= 81) & KIls (N= 8) \\
\hline Male & $27(33.3)$ & $4(50 \%)$ \\
\hline Female & $54(66.7)$ & $4(50 \%)$ \\
\hline
\end{tabular}

\section{Data Collection}


Data was collected between March and April 2019. Eight research assistants (four male and four female) with at least five years of experience in qualitative research methods and a degree in social sciences were trained for three days on study objectives and ethical conduct in qualitative data collection. KII and FGD guides had been approved in the protocol.

There were nine FGDs having six to 13 participants each and a total of 81 participants. They included nurses, midwives, clinical officers, laboratory technologists, medical officers, counsellors, nursing assistants and data officers. None of them had implemented tobacco use cessation in their clinical practice because such integration is not government policy in Uganda. FGDs were conducted in a room of preference in facilities where participants were working. Eight KIls were also conducted in respondents' preferred venues which were mostly their offices. FGDs and KIls were conducted in English by a moderator and a note taker, one a female and the other a male. They were all audio recorded after securing consent. During the FGD or KII, the moderator and note taker kept summarizing key issues from the discussion to get confirmation from the respondent. FGDs took between 45 and 80 minutes while KIls took between 25 and 40 minutes.

\section{Data Management And Analysis}

FGDs and KIls were transcribed verbatim by research assistants. Note takers' notes and observations were inserted into the text. Midway through data collection, investigators reviewed the data to ensure key issues were coming out. Data was transferred into the QDA Miner 2.0.6 (Provalis Research, Montreal, Quebec, Canada), a qualitative data analysis software. Content analysis was used to group similar responses [27]. Two investigators generated and agreed on the codes and any disagreement was resolved by mutual agreement. Meaningful units were used to generate codes which were later merged into themes. Findings have been displayed using representative quotes. COREQ reporting guidelines were used [28].

\section{Ethical Considerations}

The study was approved by the Makerere University School of Public Health Higher Degrees and Ethics Committee (487) and the Uganda National Council for Science and Technology (SS 4528). Permission was requested from and granted by heads of health facilities before data collection. Informed consent was received from all participants after being informed of study objectives and that they could withdraw anytime. Data was only accessible to the researchers.

\section{Results}

Three themes emerged. The first was that tobacco use cessation should be integrated in TB prevention and rehabilitation. Secondly, that other partners need to participate in the integration, such as care takers 
in patients' families, communities, the media and specialised facilities. Lastly, that health system gaps need to be rectified to have effective integration.

\section{1) Integration Should Go Beyond Health Facilities}

Participants indicated that tobacco use cessation activities need to be integrated into health promotion activities when sensitizing communities against TB.

"The first thing is to create awareness in the community about the relationship between tobacco use and TB. When someone understands the benefits, one will stop using tobacco" (KII 1 in-charge TB clinic)

While at health facilities, smokers should be identified from other patients so that they can receive tobacco use cessation messages alongside their other treatment.

"You identify these smokers so that you are able to give them key messages that will help them understand the relationship between TB and Tobacco use, what impact it has on the patient, on the patient's treatment outcome, and on the community." (FGD 9 Health workers)

"... when the patient is educated, he will stop and that message is given to every patient who is started on treatment" (FGD 5 Health workers)

Patients needed to be followed up after treatment so that they do not go back to tobacco use.

“...it's better to follow that person after the treatment for TB to see whether she went back to smoking or has remained without using tobacco" (KII 7 in-charge TB clinic)

"There should be follow-up of patients that have completed TB treatment on whether they have gone back to smoking or have completely stopped." (KII 8 in-charge TB clinic)

Concepts helpful to understanding the process of integrating tobacco cessation along the continuum of TB care are depicted in Fig. 1.

\section{2) Linkages with other partners in the tobacco use cessation}

Whereas participants supported tobacco use cessation activities within health facilities, they noted that they needed the support of community members and highly specialized centres.

TB treatment requires having a trusted person whom the patient chooses to support him or her. This person gives drugs to the patient who takes them under observation. These people are called TB treatment supporters. TB treatment supporters were identified as possible partners in tobacco use cessation.

"Treatment supporters are there to monitor these patients on treatment but also they can help to continuously encourage the patient on quitting tobacco smoking" (FGD 9 Health workers) 
"... Patients have a habit of leaving the bed saying they want to walk around whereas they are going to smoke somewhere where they are not seen. The treatment supporter can inform the health worker that the patient has gone to smoke" (FGD 4 Health workers)

Peers and community members are the other partners health workers saw as helpful in ensuring there is tobacco use cessation.

"We should train peers who will be in the community. Peers will follow them up." (FGD 6 Health workers)

The media was also identified as an important partner in tobacco use cessation.

"I feel the media can be used to sensitize people like on radio and newspapers so that people can get the information" (FGD 9 Health workers)

Participants indicated that those who would have developed complications needed to be referred to specialized centres.

"...for those who will have developed complications like cancer; we need to refer them to higher level facilities" (FGD 3 Health workers)

\section{3) Anticipated Challenges}

There were anticipated challenges within health facilities that needed to be addressed for effective implementation of tobacco use cessation activities.

Participants reported lack of skills for tobacco use cessation and having inadequate health workers on TB wards.

"I may be having knowledge but we are working with other staffs who are not having the knowledge for tobacco use cessation yet they are part of the team. So they may not have knowledge that they require to implement the tobacco use cessation into TB treatment" (KII 1 in-charge TB clinic)

"Health workers are not enough to provide adequate services. For example, we don't have a trained qualified counsellor to support TB patients. Sometimes a health worker can be alone at the out-patient and at the same time be on the ward to attend to patients" (KII 2 in-charge TB clinic)

However, a minority of health workers indicated that integration would not add on too much workload.

"It doesn't add any workload because we don't get many people smoking. They are mostly men and most men don't come to health facilities. The ladies who come mostly chew tobacco and that one is easily stopped once you advise them." (KII 8 in-charge TB clinic)

Documentation in facilities did not record those who use tobacco. This made it difficult to follow up those smoking. 
"...the challenge could be that there is no proper documentation of whoever is a smoker.....there is no way one can understand that this is a smoker and taking TB treatment. ... a system should be built so that all data are captured and at the end of the day you know where to start from." (FGD 2 Health workers) "... of course we also ask about the smoking. You just do it verbally but you don't document it anywhere. He may tell you that now I have reduced smoking but we don't document" (FGD 3 Health workers)

However, there were dissenting voices who indicated that the Ministry of Health tools were capturing the smokers. To them, it was an issue of data management where those who summarized the data were not giving the data on smokers.

"Ministry of Health tools are already capturing it only that by the time the form reaches the Health Management Information System (HMIS) person to track that information, you find that that part was not filled." (FGD 3 Health workers)

There was agreement across the respondents that there is lack of a robust investigation to monitor decrease in smoking.

"...currently we cannot quantify how much tobacco someone consumes ... we don't have any investigation that is currently carried out at the health facility to see how much one has reduced. In TB, you do the Gene Xpert at the beginning, then on follow-up at two months, you take off a sputum sample to see the progress of the treatment but regarding tobacco use, there is no quantification" (FGD 3 Health workers)

There was lack of Information Education Communication (IEC) materials and job aids to use in tobacco use cessation.

"I will suggest that the counselling can continue but also the IEC materials like the posters for tobacco use cessation must be provided in public places so that after counselling somebody will look at the poster and say, 'If this is the outcome, let me stop it"' (FGD 4 Health workers)

"...there is need for some job aids on tobacco use cessation because there is some other detailed information we are lacking and you can't know everything. If there are those job aids, it can help us a lot" (FGD 6 health workers)

Some facilities needed more space.

"Space is not enough for health workers to do their work. Sometimes we utilize the small space for counselling services to provide TB treatment. Our dispensing room is also used by the staff as dressing room and meeting place" (KII 2 in-charge TB clinic)

"Ideally, space has been a challenge and it is still a challenge ... at the moment the space where we are providing services is not adequate but I hope that in future we may have better space" (KII 6 in-charge TB clinic) 
However, some other facilities indicated that they had enough space depending on whether they had a designed building for specifically for TB or had small numbers of patients.

"We have a whole unit that is built for handling TB management ... we have space where we can manage them except if their number increases that is when we can face challenges" (KII 1 in-charge TB clinic)

"... we have enough space because patients can be two or three and also those who are diagnosed on TB treatment are not more than three a day, so that's an affordable number which we can handle with the given resources" (KII 7 in-charge TB clinic)

\section{Discussion}

According to health workers, integration should go beyond health facilities to communities. Linkages with communities and specialized centres were critical. Expected challenges included inadequate numbers and skills in human resources, gaps in documentation, additional supplies and more space.

Participants indicated that integration of tobacco use cessation activities should not wait for the person to be sick nor stop after declaring the patient cured. Tobacco use cessation should be integrated into TB prevention, care and post treatment support. As smoking is a risk factor for acquiring TB infection [29] integrating tobacco use cessation into TB prevention would address the incidence of TB. Healthy people should be sensitized about the relationship between tobacco use and TB. Even after TB treatment, tobacco use has been associated with reduced lung function [30]. A study in Indonesia recommended integration of TB treatment and follow up with smoking cessation [31]. A study in Hong Kong concluded that smoking cessation reduces secondary transmission and relapse of tuberculosis [32]. Tobacco use cessation needs to be integrated into the entire spectrum of TB health care continuum from prevention to post treatment management. Communities sometimes do not have proper knowledge about TB [33]. It is therefore critical that health education for TB prevention and control incorporates tobacco use cessation.

Integration of tobacco use cessation into TB treatment involves TB treatment supporters, patient's peers and the community. Treatment supporters are those people who support health workers in giving drugs to patients under the Community Based-Directly Observed Treatment Short course (CB-DOTS). A review of the CB-DOTS strategy was found to lead to improved TB treatment outcomes [34]. Integrating tobacco use cessation through these people was envisaged as an opportunity to explore. Social determinants of TB have been ascertained over a couple of studies $[31,35,36]$. The multi-sectoral collaboration in TB prevention and control cannot be overemphasized. For those who develop complications, there should be an opportunity for referral. A study in India highlighted inadequate referral to tobacco use cessation specialized centres [37]. Referral within health service delivery is a critical factor in providing continuity in provision of services. It is therefore pertinent that even in referral facilities, the integration of tobacco use cessation and TB treatment should be practiced.

While integration presents immense benefits to patients, their families and the communities they live in, facilities need to be equipped with appropriately trained human resources in adequate numbers, have an 
information management system that can track those who use tobacco and avail the health workers with the needed IEC materials, job aids and other supplies. Studies in South Africa noted a need for training and acquisition of other skills for the success of integration [38, 39]. Documentation is not only to be initiated but also maintained. Some programs in India that initiated the integration later declined in documentation of tobacco users in TB treatment programs [21]. Tailor made assessments for each facility need to be conducted for integration to be effectively done as different facilities have different capacities and resources to support additional activities.

\section{Strengths And Limitations Of This Study}

The strength of the study was that all the participants were health workers who interface with TB patients in their daily work and therefore could give informed opinions. The other strength was that sampled facilities included both urban and rural facilities hence experiences from both localities could be captured. The limitation was that the study was conducted in referral health facilities, general hospitals and high-volume health centres which may not be representative of all health facilities in the country. However, since most TB patients get treated in these high volume centres, changes in such centres could affect the highest number of patients and recommendations given by the health workers go beyond facilities to communities shared by both high level and lower level facilities.

\section{Conclusion}

Integration of tobacco use cessation in TB treatment and control should not be restricted to health facilities but should go to communities during prevention of TB and post treatment rehabilitation and management. Such integration efforts require collaborations with treatment supporters, community members, the media and specialized centres. Implementing such interventions may necessitate increasing the capacity and resources of some health facilities.

\section{Declarations}

\section{Conflict of interest}

There is no conflict of interest from any of the authors.

\section{Consent for publication}

There are no figures or other pieces of information that require consent for publication in this manuscript.

\section{Acknowledgements}

We acknowledge the support of all heads of facilities where the study was conducted for giving us permission to conduct the study in their organizations. We thank wholeheartedly the health workers who participated actively in the focus group discussions and the key informant interviews. We are also very 
grateful to the team of research assistants who travelled around the country collecting the data. To all those who supported the process in one way or another and have not been specifically mentioned above, we are very grateful.

\section{Funding}

The study was supported by the Partnership for Enhanced Engagement in Research (PEER) program administered by the National Academy of Sciences (NAS) and funded by the United States Agency for International Development (USAID) in partnership with the U.S. National Institutes of Health (NIH).

\section{Availability of data and materials}

The data used for this paper has got many personal identifiers and places common in qualitative data. It can be got on reasonable request from the Principal Investigator of the study who is the first author on this paper.

\section{Author Contributions}

ER participated in the conceptualization, proposal writing, data collection and analysis, generated the first draft of the manuscript, contributed to the review of subsequent versions approved the final version, and agrees to be accountable for the entire work.

$\mathrm{KN}$ participated in the conceptualization, proposal writing, data collection and analysis, reviewed the manuscript, approved the final version and agrees to be accountable for the entire work.

SJ participated in the conceptualization, proposal writing, contributed to the manuscript writing, approved the final version and agrees to be accountable for the entire work.

YO participated in the conceptualization, proposal writing, contributed to the manuscript writing, approved the final version and agrees to be accountable for the entire work.

HMM participated in the conceptualization, proposal writing, data analysis, contributed to the manuscript writing, approved the final version and agrees to be accountable for the entire work.

RPP participated in the conceptualization, proposal writing, contributed to the manuscript writing, approved the final version and agrees to be accountable for the entire work.

\section{References}

1. Okot-Nwang M, Wabwire-Mangen F, Kagezi VB. Increasing prevalence of tuberculosis among Mulago Hospital admissions, Kampala, Uganda (1985-1989). Tubercle lung disease: the official journal of the International Union against Tuberculosis Lung Disease. 1993;74(2):121-5.

2. Government of Uganda. Annual Health Sector Performance Report, Financial Year 2018/2019. Kampala: Ministry of Health; 2019. 
3. World Health Organization. Global tuberculosis report 2019. Geneva: World Health Organization; 2019. Licence: CC BY-NC-SA 3.0 IGO.; 2019.

4. World Health Organization. Global tuberculosis report 2014. Geneva: World Health Organization; 2014.; 2014.

5. Kirenga BJ, Ssengooba W, Muwonge C, Nakiyingi L, Kyaligonza S, Kasozi S, Mugabe F, Boeree M, Joloba M, Okwera A. Tuberculosis risk factors among tuberculosis patients in Kampala, Uganda: implications for tuberculosis control. BMC Public Health. 2015;15:13.

6. Ministry of Health. Guidelines for Governance and Management Structures. Kampala: Ministry of Health; 2013.

7. Government of Uganda. THE TOBACCO CONTROL ACT, 2015. In: ACTS SUPPLEMENT No 11 to The Uganda Gazette No 67, Volume CVIII, dated 18th November, '2015. Edited by Uganda Go. Entebbe: UPPC; 2015.

8. Patra J, Bhatia M, Suraweera W, Morris SK, Patra C, Gupta PC, Jha P. Exposure to second-hand smoke and the risk of tuberculosis in children and adults: a systematic review and meta-analysis of 18 observational studies. PLoS Med. 2015;12(6):e1001835. discussion e1001835.

9. Underner M, Perriot J, Peiffer G, Meurice JC, Dautzenberg B. [Smoking and adherence to antituberculosis treatment]. Rev Mal Respir. 2016;33(2):128-44.

10. Bagchi S, Ambe G, Sathiakumar N. Determinants of poor adherence to anti-tuberculosis treatment in mumbai, India. International journal of preventive medicine. 2010;1(4):223-32.

11. Mahishale V, Patil B, Lolly M, Eti A, Khan S. Prevalence of Smoking and Its Impact on Treatment Outcomes in Newly Diagnosed Pulmonary Tuberculosis Patients: A Hospital-Based Prospective Study. Chonnam medical journal. 2015;51(2):86-90.

12. Chiang YC, Lin YM, Lee JA, Lee CN, Chen HY. Tobacco consumption is a reversible risk factor associated with reduced successful treatment outcomes of anti-tuberculosis therapy. International journal of infectious diseases: IJID : official publication of the International Society for Infectious Diseases. 2012;16(2):e130-5.

13. Aguilar JP, Arriaga MB, Rodas MN, Martins Netto E. Smoking and pulmonary tuberculosis treatment failure: a case-control study. Jornal brasileiro de pneumologia: publicacao oficial da Sociedade Brasileira de Pneumologia e Tisilogia. 2019;45(2):e20180359.

14. Masjedi MR, Hosseini M, Aryanpur M, Mortaz E, Tabarsi P, Soori H, Emami H, Heidari G, Dizagie MK, Baikpour M. The effects of smoking on treatment outcome in patients newly diagnosed with pulmonary tuberculosis. The international journal of tuberculosis lung disease: the official journal of the International Union against Tuberculosis Lung Disease. 2017;21(3):351-6.

15. Leveri TH, Lekule I, Mollel E, Lyamuya F, Kilonzo K. Predictors of Treatment Outcomes among Multidrug Resistant Tuberculosis Patients in Tanzania. Tuberculosis research treatment. 2019;2019:3569018.

16. Wang J, Shen H. Review of cigarette smoking and tuberculosis in China: intervention is needed for smoking cessation among tuberculosis patients. BMC Public Health. 2009;9:292. 
17. Owusu D, Wang KS, Quinn M, Aibangbee J, John RM, Mamudu HM. Health Care Provider Intervention and Utilization of Cessation Assistance in 12 Low- and Middle-Income Countries. Nicotine tobacco research: official journal of the Society for Research on Nicotine Tobacco. 2019;21(2):188-96.

18. Omole OB, Ngobale KN, Ayo-Yusuf OA. Missed opportunities for tobacco use screening and brief cessation advice in South African primary health care: a cross-sectional study. BMC Fam Pract. 2010;11:94.

19. Odukoya O, Jamda M, Onigbogi O, Uguru N, Onigbogi M, James F, Faseru B, Leischow S, Ayo-Yusuf O. Tobacco Cessation Interventions in Tertiary Hospitals in Nigeria: An Audit of Patient Records. Nicotine \& tobacco research: official journal of the Society for Research on Nicotine and Tobacco 2017.

20. Abdullah AS, Stillman FA, Yang L, Luo H, Zhang Z, Samet JM. Tobacco use and smoking cessation practices among physicians in developing countries: a literature review (1987-2010). Int J Environ Res Public Health. 2013;11(1):429-55.

21. Gupte HA, Zachariah R, Sagili KD, Thawal V, Chaudhuri L, Verma H, Dongre A, Malekar A, Rigotti NA. Integration of tobacco cessation and tuberculosis management by NGOs in urban India: a mixedmethods study. Public health action. 2018;8(2):50-8.

22. Goel S, Kathiresan J, Singh P, Singh RJ. Effect of a brief smoking cessation intervention on adult tobacco smokers with pulmonary tuberculosis: A cluster randomized controlled trial from North India. Indian J Public Health. 2017;61(Suppl 1):47-53.

23. Khan ME, Manderson L. Focus Groups in Tropical Diseases Research. Health Policy Plann. 1992;7(1):56-66.

24. Dahlgren L, Emmelin M, Winkvist A. Qualitative Methodology for International Public Health. Umea: Umea University; 2004.

25. Marshall C, Rossman GB: Designing Qualitative Research, 4th Edition edn. London: Sage Publications; 2006.

26. Rice PL, Ezzy D. Qualitative Research Methods - A Health Focus. Oxford: Oxford University Press; 1999.

27. Graneheim UH, Lundman B. Qualitative content analysis in nursing research: concepts, procedures and measures to achieve trustworthiness. Nurse Educ Today. 2004;24(2):105-12.

28. O'Brien BC, Harris IB, Beckman TJ, Reed DA, Cook DA. Standards for reporting qualitative research: a synthesis of recommendations. Academic medicine: journal of the Association of American Medical Colleges. 2014;89(9):1245-51.

29. Ganmaa D, Khudyakov P, Buyanjargal U, Baigal D, Baatar M, Enkhamgalan N, Erdenebaatar S, Ochirbat B, Burneebaatar B, Purevdorj E, et al. Risk factors for active tuberculosis in 938 QuantiFERON-positive schoolchildren in Mongolia: a community-based cross-sectional study. BMC Infect Dis. 2019;19(1):532.

30. Gandhi K, Gupta S, Singla R. Risk factors associated with development of pulmonary impairment after tuberculosis. Indian J Tuberc. 2016;63(1):34-8. 
31. Wardani D, Wahono EP. Predominant Determinants of Delayed Tuberculosis Sputum Conversion in Indonesia. Indian journal of community medicine: official publication of Indian Association of Preventive Social Medicine. 2019;44(1):53-7.

32. Leung CC, Yew WW, Chan CK, Chang KC, Law WS, Lee SN, Tai LB, Leung EC, Au RK, Huang SS, et al. Smoking adversely affects treatment response, outcome and relapse in tuberculosis. Eur Respir $\mathrm{J}$. 2015;45(3):738-45.

33. Mangesho PE, Shayo E, Makunde WH, Keto GB, Mandara Cl, Kamugisha ML, Kilale AM, Ishengoma DR. Community knowledge, attitudes and practices towards tuberculosis and its treatment in Mpwapwa district, central Tanzania. Tanzania health research bulletin. 2007;9(1):38-43.

34. Zhang H, Ehiri J, Yang H, Tang S, Li Y. Impact of Community-Based DOT on Tuberculosis Treatment Outcomes: A Systematic Review and Meta-Analysis. PloS one. 2016;11(2):e0147744.

35. Khan MK, Islam MN, Ferdous J, Alam MM. An Overview on Epidemiology of Tuberculosis. Mymensingh medical journal: MMJ. 2019;28(1):259-66.

36. Kilabuk E, Momoli F, Mallick R, Van Dyk D, Pease C, Zwerling A, Potvin SE, Alvarez GG. Social determinants of health among residential areas with a high tuberculosis incidence in a remote Inuit community. J Epidemiol Commun Health. 2019;73(5):401-6.

37. Navya N, Jeyashree K, Madhukeshwar AK, Anand T, Nirgude AS, Nayarmoole BM, Isaakidis P. Are they there yet? Linkage of patients with tuberculosis to services for tobacco cessation and alcohol abuse - a mixed methods study from Karnataka, India. BMC Health Serv Res. 2019;19(1):90.

38. Scott V, Chopra M, Azevedo V, Caldwell J, Naidoo P, Smuts B. Scaling up integration: development and results of a participatory assessment of HIV/TB services, South Africa. Health research policy systems. 2010;8:23.

39. Warsi S, Elsey H, Boeckmann M, Noor M, Khan A, Barua D, Nasreen S, Huque S, Huque R, Khanal S, et al. Using behaviour change theory to train health workers on tobacco cessation support for tuberculosis patients: a mixed-methods study in Bangladesh, Nepal and Pakistan. BMC Health Serv Res. 2019;19(1):71.

\section{Figures}




\begin{tabular}{|c|c|c|c|c|c|}
\hline 苋 & $\begin{array}{c}\text { Health } \\
\text { promotion }\end{array}$ & $\begin{array}{l}\text { Preventive } \\
\text { services }\end{array}$ & $\begin{array}{l}\text { Detection } \\
\text { services }\end{array}$ & Treatment & $\begin{array}{l}\text { Rehabilitation } \\
\text { and control }\end{array}$ \\
\hline 票 & $\begin{array}{l}\text { Community } \\
\text { sensitization } \\
\text { on the } \\
\text { effects of } \\
\text { tobacco use }\end{array}$ & $\begin{array}{l}\text { Correct } \\
\text { identification } \\
\text { of symptoms }\end{array}$ & $\begin{array}{l}\text { Directing } \\
\text { them to } \\
\text { appropriate } \\
\text { care }\end{array}$ & $\begin{array}{l}\text { Counselling } \\
\text { and } \\
\text { treatment } \\
\text { support }\end{array}$ & $\begin{array}{l}\text { Post cessation } \\
\text { support }\end{array}$ \\
\hline 总 & $\begin{array}{l}\text { Healthy } \\
\text { Community } \\
\text { members }\end{array}$ & $\begin{array}{l}\text { People at risk } \\
\text { like those } \\
\text { sharing } \\
\text { cigarettes }\end{array}$ & $\begin{array}{l}\text { New patients } \\
\text { starting on } \\
\text { treatment }\end{array}$ & $\begin{array}{l}\text { Patients } \\
\text { undergoing } \\
\text { treatment }\end{array}$ & $\begin{array}{l}\text { Persons who } \\
\text { have finished } \\
\text { treatment }\end{array}$ \\
\hline
\end{tabular}

Figure 1

Engagement of different populations in the tobacco use cessation activities

\section{Supplementary Files}

This is a list of supplementary files associated with this preprint. Click to download.

- ToolFocusGroupDiscussionGuide.doc

- ToolKeyInformantInterviewGuide.docx

- FilledCOREQguidelineschecklist.docx 